\title{
Factors related to the practice of breast self examination (BSE) and Pap smear screening among Malaysian women workers in selected electronics factories
} HL Chee*1, S Rashidah ${ }^{2}$, K Shamsuddin ${ }^{3}$ and O Intan ${ }^{4}$

\begin{abstract}
Address: ${ }^{1}$ Department of Community Health, Faculty of Medicine and Health Sciences, Universiti Putra Malaysia, 43400 UPM Serdang, Selangor, Malaysia, ${ }^{2}$ Women's Health Development Unit, School of Medical Sciences, Universiti Sains Malaysia, 16150 Kubang Kerian, Kelantan, Malaysia, ${ }^{3}$ Department of Community Health, Faculty of Medicine, Universiti Kebangsaan Malaysia, 56000 Cheras, Kuala Lumpur, Malaysia and ${ }^{4}$ School of Management, Universiti Sains Malaysia, 11800 Minden, Penang, Malaysia
\end{abstract}

Email: HL Chee* - hengleng@medic.upm.edu.my; S Rashidah - rashidah@kb.usm.my; K Shamsuddin - khadijah@mail.hukm.ukm.my; O Intan - intan@usm.my

* Corresponding author

Published: 28 May 2003

BMC Women's Health 2003, 3:3

This article is available from: http://www.biomedcentral.com/l472-6874/3/3

(C) 2003 Chee et al; licensee BioMed Central Ltd. This is an Open Access article: verbatim copying and redistribution of this article are permitted in all media for any purpose, provided this notice is preserved along with the article's original URL.

\begin{abstract}
Background: The Malaysian Ministry of Health promotes breast self-examination (BSE) for all women, and Pap smear screening every three years for all sexually active women ages 20 years and above. The objectives of this paper were to examine the practice of these two screening tests among women production workers in electronics factories, and to identify factors related to practice.
\end{abstract}

Methods: This was a cross-sectional survey of women production workers from ten electronics factories. Data was collected by a self-administered questionnaire from a total of I,720 women. The chi-square test, odds ratio and binomial logistic regression were used in bivariate and multivariate analysis.

Results: Prevalence rates were $24.4 \%$ for BSE once a month, and $18.4 \%$ for Pap smear examination within the last three years. Women who were significantly more likely to perform BSE every month were 30 years and older, Malays, with upper secondary education and above, answered the BSE question correctly, and had a Pap smear within the last three years. The proportion of women who had a Pap smear within the last three years were significantly higher among those who were older, married, with young children, on the contraceptive pill or intra-uterine device, had a medical examination within the last five years, answered the Pap smear question correctly, and performed BSE monthly.

Conclusion: Screening practice rates in this study were low when compared to national rates. Socio-demographic and health care factors significantly associated with screening practice are indicative of barriers which should be further understood so that more effective educational and promotional strategies could be developed.

\section{Background}

The effectiveness of breast self examination (BSE) in low- ering breast cancer mortality has been extensively studied. After reviewing studies published between 1966 to 
October 2000, the Canadian Task Force on Preventive Health Care found no evidence that routine BSE teaching or practice is beneficial in terms of lower risk of breast cancer death, or earlier stage of cancer at diagnosis [1]. Instead, they found that women who were taught BSE and practised it faced a higher rate of physician visits, and higher risk of anxiety and benign biopsies. Based on these findings, they recommended that routine teaching of BSE be discontinued, particularly for women aged 40 to 69 years. Following on this, the final results of a 10-11 year randomized controlled trial in Shanghai were published, confirming that intensive instruction in BSE did not reduce breast cancer deaths [2].

Nevertheless, there is disagreement with the recommendation of discontinuing BSE advocacy among women [35]. Those who disagree point out that many breast tumours are discovered by women themselves, and that the practice of BSE makes women more aware of their breasts and therefore more likely to detect tumours, even if they did not detect them while doing BSE. In developing countries, it is considered to be a simple, inexpensive, non-invasive, and non-hazardous intervention, which is not only acceptable, cost-effective and appropriate, but also encourages women to take an active responsibility in preventive health [6]. It should be pointed out, however, that spending health resources on BSE, if it is ineffective, detracts from focussing on trying to find other ways of prevention.

On the other hand, the utilization of the Pap smear for the early detection of cervical cancer is better established, although the reliability of the test varies and is dependent on the expertise of the health professionals who take the smear as well as those who examine it [7]. In developed countries such as the United Kingdom, the recognition that Pap smear screening could result in false alarms or false reassurance, overdiagnosis and overtreatment has led to a recent emphasis on 'informed uptake', that is, that women should be made fully aware of all positive and negative consequences before undergoing screening. In some developing countries, the cost-effectiveness of Pap smear screening programmes has been questioned because they have not resulted in declining cervical cancer rates due to inefficient screening programmes and poor quality tests [8].

In Malaysia, breast cancer is the leading cause of cancer deaths among women, accounting for about $11 \%$ of all medically certified deaths in the country $[9,6]$. The national incidence rate is not available, but it is estimated that 1,200 new cases occur every year, and an increasing trend of cases among younger women has been observed. The Ministry of Health promotes the practice of monthly BSE for women above the age of 20 years, and annual clin- ical breast examination by a medical or paramedical personnel [6]. Mammography is not widely available as a screening method, and it is only recommended for women at special risk of breast cancer, identified as those who have had breast cancer in one breast, and those with a mother or sister who have breast cancer. BSE is primarily taught by nurses to women who attend government health clinics, as well as family planning clinics run by the non-governmental family planning associations.

Unlike breast cancer, mortality from cervical cancer has declined in relative importance, although it is still the second most important cancer among women in Malaysia $[10,11]$. The national incidence rate for cervical cancer is not known, but over the last ten years, there have been 2,000-3,000 admissions per year to government hospitals. The policy of the Ministry of Health is to promote and provide Pap smear screening to all women between 20-65 years of age [11]. Official recommendation is for women to undergo the Pap smear test annually in the initial two years, and subsequently, once every three years, with priorities for sexually active women who are more than 35 years old, have more than five children, have practised contraception for more than five years or who are new acceptors of family planning services, and women diagnosed with sexually transmitted diseases. Women who attend postnatal and family planning services are primary targets.

Although the policy is to target all sexually active women, in practice, married women have more access due to a variety of reasons. One of the reasons is that this is a recent policy change, and prior to 1995 , when a nation-wide campaign on prevention of breast and cervical cancer was carried out, the official policy was to provide cervical cancer screening for married women only.

There is currently no system in the country for collecting routine information on the practice of BSE among women, and available information on Pap smear screening is only from government facilities. As such, both were included in the scope of the country's Second National Health and Morbidity Survey (NHMS) 1996 [6,11].

Likewise, reflecting national concerns, a governmentfunded research project on health status and lifestyle of women workers in the electronics industry also included these two topics. This paper uses data from this recent study to examine the prevalence of BSE and Pap smear screening and the relationship of various socio-demographic and health care factors with the practice of the two screening tests among electronics women workers. 


\section{Methods \\ Selection of factories}

This was a cross-sectional analytical survey of women workers in selected electronics factories carried out by four research centres - Universiti Sains Malaysia, Penang (USM Pg), Universiti Sains Malaysia, Kelantan (USM Kel), Universiti Kebangsaan Malaysia (UKM) and Universiti Putra Malaysia with the help of the National Institute for Occupational Safety and Health (UPM-NIOSH). The inclusion criteria used for selecting factories was that they must be electronics assembly factories, have at least 500 or more women production workers and have been in production for at least two years. Four geographical areas were identified for the research, and each research centre took responsibility for one area - USM Pg for Penang (a northwestern state), USM Kel for Kota Baru (the capital of the north-eastern state of Kelantan), UKM for Hulu Kelang Free Trade Zone (FTZ) and UPM-NIOSH for Bangi FTZ (both FTZs are in the west-central state of Selangor). A target sample size of 2000 women workers, or 500 per centre, was determined as sufficient for analysis, based upon limited resources.

In Kota Baru, there were three factories which fulfilled the criteria. All three were invited to participate in the study, and one agreed. In the Hulu Kelang FTZ, there were two eligible factories, both of which were invited, but only one agreed. In the Bangi FTZ all seven eligible factories were invited but only five agreed to participate. The UPMNIOSH centre was not able to meet the target number of 500 respondents from these five factories, and through personal contacts, managed to get the cooperation of another factory located in the Sungei Way FTZ (also in Selangor state). In Penang, 15 factories were purposively selected from 160 in the Penang Development Corporation (Corporate Investment Section) 1995 list based on the inclusion criteria. These 15 factories were invited to participate in the study, but only one agreed. In order to make up the target sample size, the USM Pg centre enlisted the cooperation of a factory in Sungei Petani (in the northwestern state of Kedah) through a personal contact.

In summary therefore, a total of 27 factories in four geographical areas were invited to take part in the study, but only eight factories agreed to participate. In order to achieve the target sample size, two more factories were included, both of which were not within the original four research areas. Finally, therefore, ten factories located in six areas participated in the study.

\section{Selection of respondents and data collection}

Varying levels of cooperation were obtained from the ten factories in the selection of respondents and in data collection. It was determined, however, that respondents had to be women between the ages of 17 and 55 years, Malaysian citizens, and had worked at least a year as production workers (below supervisory level) in the factory where they were presently working. The requisite age span was determined based upon the legal age for working and the retirement age. In Kota Baru (Factory A) (Table 1), full cooperation was obtained from the factory, and all the women workers who fitted the selection criteria were included in the study. In the Penang factory (Factory B), full cooperation was also obtained, and researchers were able to randomly select 250 workers from a list provided by the management. In these two factories, the selected workers were released during working time to take part in the survey, and there were no workers who declined to participate. The percentage of completed questionnaires out of the total number of workers in the sample were $97.6 \%$ for Factory A and $98.0 \%$ for Factory B.

In all the other factories, the management gave their cooperation only to the extent of publicising the study (by posting notices and making announcements) and asking for volunteers. The volunteers had to participate in the study either during break or meal times, or in their own free time. Three factories did not permit data collection on factory premises, but allowed researchers access to their hostels; the catchment population in these factories were therefore limited to the hostel occupants. In all these cases, participation was much lower than in Factory A and Factory $\mathrm{B}$, and the percentage of completed questionnaires from the catchment population ranged from $12.4 \%$ to $35.7 \%$ (Table 1 ). The overall response rate, strictly speaking, could not be calculated, but with the above caveats in mind, it may be estimated at $18.2 \%$.

Data collection was carried out between March 1999 and September 2000, with much delay encountered while obtaining consent from factories. During the survey, batches of 2-10 respondents attended sessions where they were first briefed on the purpose of the survey, and assured confidentiality, before filling in a self-administered questionnaire in the presence of research assistants. The research assistants verbally interviewed those who faced language or literacy barriers in filling in the questionnaires themselves (but these cases were generally less than $5 \%$ ).

\section{Instrument and pre-test}

The questionnaire was in Malay, the national language, and had been pre-tested among 60 women workers who were randomly selected from a factory in Penang (not included in the sample for the study). The pre-test was carried out in September 1998. 
Table I: The sample

\begin{tabular}{|c|c|c|c|c|c|c|c|c|c|}
\hline $\begin{array}{l}\text { Research } \\
\text { Centre }\end{array}$ & Location & Factory & $\begin{array}{l}\text { Estimated } \\
\text { no. of } \\
\text { women } \\
\text { production } \\
\text { workers in } \\
\text { factory }\end{array}$ & $\begin{array}{c}\text { No. of } \\
\text { women } \\
\text { workers in } \\
\text { sample (No. } \\
\text { of question- } \\
\text { naires } \\
\text { obtained) }\end{array}$ & $\begin{array}{l}\text { No. of } \\
\text { question- } \\
\text { naires in } \\
\text { dataset } \\
\text { (after } \\
\text { cleaning) }\end{array}$ & $\begin{array}{l}\text { Selection of } \\
\text { workers }\end{array}$ & $\begin{array}{l}\text { Respon } \\
\text { se rate } \\
\text { (\%) }\end{array}$ & $\begin{array}{l}\text { Location } \\
\text { for data } \\
\text { collection }\end{array}$ & $\begin{array}{l}\text { Time for data } \\
\text { collection }\end{array}$ \\
\hline USM Kel & Kota Baru & $A$ & 500 & 250 & 244 & All eligible workers & 97.61 & Factory & Working time \\
\hline \multirow[t]{2}{*}{ USM Pg } & Penang & B & 800 & 255 & 250 & Random Sampling & $98.0^{1}$ & Factory & Working time \\
\hline & Sungei Petani & C & 700 & 260 & 250 & Volunteers & $(35.7)^{2}$ & Factory & Own time \\
\hline UKM & $\begin{array}{l}\text { Hulu Kelang } \\
\text { FTZ }\end{array}$ & $\mathrm{D}$ & 3500 & 505 & 490 & Volunteers & $(14.0)^{2}$ & Factory & Own time \\
\hline \multirow[t]{6}{*}{ UPM } & Bangi FTZ & $E$ & 500 & 526 & 486 & Volunteers & $(12.4)^{2}$ & $\begin{array}{l}\text { Factory and } \\
\text { hostel }\end{array}$ & Own time \\
\hline & Bangi FTZ & $\mathrm{F}$ & 1000 & & & & & & \\
\hline & Bangi FTZ & $\mathrm{G}^{3}$ & II 100 (400) & & & & & & \\
\hline & Bangi FTZ & $\mathrm{H}^{3}$ & $600(230)$ & & & & & & \\
\hline & Bangi FTZ & $\mathrm{I}^{3}$ & $1200(500)$ & & & & & & \\
\hline & $\begin{array}{l}\text { Sungei Way } \\
\text { FTZ }\end{array}$ & $\mathrm{J}$ & 1300 & & & & & & \\
\hline All & & Total & $11200^{4}$ & 1796 & 1720 & & $(18.2)^{4}$ & & \\
\hline
\end{tabular}

IResponse rate calculated from number of questionnaires in dataset (after cleaning) as percentage of women workers in sample. ${ }^{2}$ Response rate calculated from number of questionnaires in dataset (after cleaning) as percentage of estimated number of women workers in the population from which the volunteers were drawn, i.e. the catchment population. For Factory C, D, E, F and J, the catchment population is the estimated number of women workers in the factory, while for Factory G, H and I, it is the estimated number of women workers in the hostels. ${ }^{3}$ These factories only allowed data collection at their hostels, not on factory premises. Estimated number of occupants in their hostels are given in brackets. ${ }^{4} \mathrm{Although}$ the total estimated number of women workers in all the factories is 11,200 , however, if we consider the catchment population only, that is, for those factories that only allowed for data collection in hostels we only take into consideration the number of women workers in the hostels, then the total is 3,930 for UPM Centre, and 9,430 for all research centres. The overall response rate is therefore I,720 from 9,430, which is $18.2 \%$.

\section{Definition of variables and data analysis}

The practice of Pap smear screening was defined as having had a test done within the last three years, while the practice of BSE was defined as doing BSE at least once a month. Postnatal and family planning visits were factors of interest since Pap smear screening and BSE are advocated through these two channels in Malaysia. The variable of having at least one young child, that is, preschool age (6 years) or younger, was identified as a proxy measure for having had recent contact with postnatal health care service.

Currently using either the contraceptive pill or intra-uterine device (IUD) was used to reflect contact with family planning services because other methods of contraception used (condom, spermicidal cream, withdrawal, herbal medicine, rhythm) did not require contact with family planning services, while tubal ligation only required a one-off visit. Knowledge was tested by true or false answers to the questions "BSE should be done every month before the menstrual period" and "Pap smear is a test to identify cervical cancer". The correct answer for the BSE question was 'false', and for the Pap smear question, it was 'true'.
Data were coded prior to entry, merged and analysed using SPSS version 10.0. The chi-square test was used to test the association of sociodemographic and health care factors with the practice of BSE and Pap smear screening. Odds ratios (OR) were calculated and interpreted as positive odds ratios (POR), following the example of Ejlertsson et al. [12], who had defined the POR as an indicator of positive health or practices rather than the conventional odds ratio that is used as a measure of risk. For ease of interpretation, the OR was consistently calculated for the group with a higher proportion of positive health behaviour compared to the group with a lower proportion of positive health behaviour. Variables of interest were used in logistic regression to yield adjusted odds ratios.

\section{Results \\ Socio-demographic and health care factors}

This was a fairly young group of women, with mean age of $30.1 \pm 7.9$ years, and more than half $(53.7 \%)$ less than 30 years old (Table 2 ). The majority were Malays $(78.9 \%)$, and most had reached at least a secondary level of education (31.3\% lower secondary, 58.3\% upper secondary, $5.8 \%$ higher). The sample was almost equally divided into single $(48.7 \%)$ and married $(47.0 \%)$ women, with a small proportion who were either divorced or widowed $(4.4 \%)$. 
Table 2: Background characteristics of study population $(n=1720)$

\begin{tabular}{|c|c|c|}
\hline & \multicolumn{2}{|c|}{ Distribution of respondents } \\
\hline & No. & $\%$ \\
\hline \multicolumn{3}{|l|}{ Age group (yrs) } \\
\hline$\leq 20$ & 69 & 4.0 \\
\hline $20-29$ & 854 & 49.7 \\
\hline $30-39$ & 539 & 31.3 \\
\hline $40-49$ & 244 & 14.2 \\
\hline$\geq 50$ & 14 & 0.8 \\
\hline Mean age (yrs) $( \pm S D)$ & \multicolumn{2}{|c|}{$30.1 \pm 7.9$} \\
\hline \multicolumn{3}{|l|}{ Ethnicity } \\
\hline Malay & 1357 & 78.9 \\
\hline Non-Malay & 363 & 21.1 \\
\hline \multicolumn{3}{|l|}{ Educational attainment } \\
\hline No formal schooling & 7 & 0.3 \\
\hline Primary & 74 & 4.3 \\
\hline Lower secondary & 538 & 31.3 \\
\hline Upper secondary & 1002 & 58.3 \\
\hline Higher than upper secondary & 99 & 5.8 \\
\hline \multicolumn{3}{|l|}{ Marital status } \\
\hline Single & 837 & 48.7 \\
\hline Married & 808 & 47.0 \\
\hline Divorced/ widowed & 75 & 4.3 \\
\hline \multicolumn{3}{|l|}{ Pregnancy Status } \\
\hline Ever pregnant & 676 & 39.3 \\
\hline Currently pregnant & 101 & 5.9 \\
\hline Never pregnant & 943 & 54.8 \\
\hline \multicolumn{3}{|l|}{ Young children (preschool or younger) } \\
\hline At least one & 491 & 28.5 \\
\hline None & 1229 & 71.5 \\
\hline \multicolumn{3}{|l|}{ Contraception } \\
\hline Currently using & 259 & 15.1 \\
\hline Currently not using & $|46|$ & 84.9 \\
\hline \multicolumn{3}{|l|}{ Types of contraception 1} \\
\hline Contraceptive pill & 131 & 7.6 \\
\hline IUD & 49 & 2.8 \\
\hline Tubal ligation & 29 & 1.7 \\
\hline Condom & 15 & 0.9 \\
\hline Withdrawal & 14 & 0.8 \\
\hline Others (herbal, rhythm, spermicide) & 38 & 2.2 \\
\hline \multicolumn{3}{|l|}{ Medical examination within last 5 years } \\
\hline Yes & 775 & 45.1 \\
\hline No & 945 & 54.9 \\
\hline
\end{tabular}

IRespondents may be using more than one method

There were $5.9 \%$ who were pregnant at the time of the study, while $28.5 \%$ of the women had young children who were of preschool age (six years) or younger.

While $15.1 \%$ of the women were currently using contraception, the types used included condoms, spermicidal cream, herbal medicines, and others, all of which do not require attendance at health clinics. Among this $15.1 \%$, $7.6 \%$ were on the contraceptive pill and $2.8 \%$ were using the IUD, both of which require women to be in contact with health care services. Women who had tubal ligation $(1.7 \%)$ would not have had to make use of health care services after the operation had been completed. Among the women, $45.1 \%$ reported having had a medical examination within the last five years. The type of examination, however, was not specified, and it could encompass either a pre-employment examination, a specific exposurerelated examination related to type of work, or a general medical examination sought by the woman herself.

\section{Practice of BSE and pap smear screening}

Although $79.1 \%$ of the women had heard about the BSE, and $53.0 \%$ knew how to conduct the examination, only $44.8 \%$ had ever done the examination, while $24.4 \%$ said that they do it once a month (Table 3 ). Likewise, although $25.3 \%$ had ever had the Pap smear, only $18.4 \%$ had their last examination within the last three years.

Women who were significantly more likely to do BSE every month were older, more highly educated, ever married, ever pregnant, had young children, had a medical examination in the last five years, had a Pap smear within the last three years, and gave a correct response to the question on when to do the BSE (Tables 4 and 5). However, BSE practice was not significantly associated with ethnicity or the use of the contraceptive pill or IUD.

Similarly, women who had a Pap smear within the last three years were significantly more likely to be older, ever married, ever pregnant, had young children, had a medical examination in the last five years, answered correctly the question on the purpose of Pap smear, and did BSE every month. In contrast to women who practise BSE however, they were also significantly more likely to be non-Malays, less educated, and using the contraceptive pill or IUD.

Table 6 shows the crude and adjusted odds ratios for the practice of BSE and Pap smear screening by the factors of interest. Women who were more than 30 years old had 1.53 times higher odds of doing BSE monthly $(95 \% \mathrm{CI}=$ 1.23-1.91) and 6.82 times higher odds of having had a Pap smear within the last three years $(95 \% \mathrm{CI}=5.13-$ 9.07 ) when compared with women who were 30 years old or younger. The number of never married women who had practised Pap smear screening was so small as to render the analysis imprecise (OR 153, 95\% CI $=49$ 478).

The logistic regression model for BSE contained ten covariates, and after adjusting, the practice of BSE was found to be significantly higher among older women (Adj OR $1.36,95 \% \mathrm{CI}=1.04-1.79$ ), Malays (Adj OR $1.55,95 \% \mathrm{CI}$ $=1.13-2.12$ ), women with upper secondary education 
Table 3: Practice of breast self-examination and pap smear screening among study population $(\mathrm{n}=\mathbf{1 7 2 0})$

\begin{tabular}{|c|c|c|}
\hline & \multicolumn{2}{|c|}{ Distribution of respondents } \\
\hline & No. & $\%$ \\
\hline \multicolumn{3}{|l|}{ Breast self-examination } \\
\hline Have heard about it & 1360 & 79.1 \\
\hline Know how to conduct the examination & 911 & 53.0 \\
\hline Have ever done the examination & 769 & 44.8 \\
\hline \multicolumn{3}{|l|}{ Frequency of examination } \\
\hline Once a month & 419 & 24.4 \\
\hline Once every 2 months & 111 & 6.5 \\
\hline Once every 3 months & 81 & 4.7 \\
\hline Once every 6 months & 79 & 4.6 \\
\hline Annually & 79 & 4.6 \\
\hline \multicolumn{3}{|l|}{ Pap-smear } \\
\hline Have heard about it & 1232 & 71.6 \\
\hline Have ever done the examination & 434 & 25.3 \\
\hline \multicolumn{3}{|l|}{ Last examination } \\
\hline$\leq 3$ years & 316 & 18.4 \\
\hline$>3$ years & 118 & 6.9 \\
\hline
\end{tabular}

Table 4: Practice of breast self examination (BSE) and Pap smear screening by sociodemographic variables $(n=1720)$

\begin{tabular}{|c|c|c|c|c|c|c|c|c|}
\hline & \multicolumn{2}{|c|}{ Do BSE every month } & \multirow[b]{2}{*}{$\chi^{2}$} & \multirow[b]{2}{*}{$\mathrm{P}$} & \multicolumn{2}{|c|}{ Pap smear in last 3 years } & \multirow[b]{2}{*}{$\chi^{2}$} & \multirow[b]{2}{*}{$P$} \\
\hline & Yes & No & & & Yes & No & & \\
\hline Age & & & 13.8 & $0.000 * * *$ & & & 204 & $0.000 * * *$ \\
\hline$\leq 30$ years $(n=1010)$ & $213(21.1)$ & 797 (78.9) & & & $72(7.1)$ & $938(92.9)$ & & \\
\hline$>30$ years $(n=710)$ & $206(29.0)$ & $504(71.0)$ & & & $244(34.4)$ & $466(65.6)$ & & \\
\hline Ethnicity & & & 3.7 & 0.055 & & & 20.7 & $0.000 * * *$ \\
\hline Non-Malay $(n=363)$ & $74(20.4)$ & $289(79.6)$ & & & $97(26.7)$ & $266(73.3)$ & & \\
\hline Malay $(n=1357)$ & $345(25.4)$ & $1012(74.6)$ & & & $219(16.1)$ & 1138 (83.9) & & \\
\hline Educational attainment & & & 3.9 & $0.049 *$ & & & 10.3 & $0.001^{* * *}$ \\
\hline$\leq$ Lower secondary $(n=619)$ & $133(2 \mid .5)$ & $486(78.5)$ & & & $139(22.5)$ & $480(77.5)$ & & \\
\hline$\geq$ Upper secondary $(\mathrm{n}=\mathrm{I} \mid \mathrm{O} \mathrm{I})$ & $286(26.0)$ & $815(74.0)$ & & & $177(16.1)$ & $924(83.9)$ & & \\
\hline Marital status & & & 15.8 & $0.000 * * *$ & & & 350 & $0.000 * * *$ \\
\hline Never married $(n=837)$ & $168(20.1)$ & $669(79.9)$ & & & $3(0.4)$ & $834(99.6)$ & & \\
\hline Ever married $(n=883)$ & $251(28.4)$ & 632 (7I.6) & & & $313(35.4)$ & $570(64.6)$ & & \\
\hline Pregnancy Status & & & 17.3 & $0.000 * * *$ & & & 340 & $0.000^{* * *}$ \\
\hline Never pregnant $(n=943)$ & $193(20.5)$ & $750(79.5)$ & & & $26(2.8)$ & 917 (97.2) & & \\
\hline Ever pregnant $(n=676)$ & $198(29.3)$ & $478(70.7)$ & & & $256(37.9)$ & $420(62.1)$ & & \\
\hline Currently pregnant $(n=101)$ & $28(27.7)$ & $73(72.3)$ & & & $34(33.7)$ & $67(66.3)$ & & \\
\hline Young children & & & 7.4 & $0.006 * *$ & & & 91.3 & $0.000 * * *$ \\
\hline At least one $(n=49 I)$ & $142(28.9)$ & $349(7 I .1)$ & & & $160(32.6)$ & $331(67.4)$ & & \\
\hline None $(n=1229)$ & $277(22.5)$ & $952(77.5)$ & & & $156(12.7)$ & $1073(87.3)$ & & \\
\hline
\end{tabular}

$*_{p}<0.05, *_{p}<0.01, * * * p<0.001$

and above (Adj OR 1.38, 95\% CI = 1.07-1.78), women who had had a Pap smear within the last three years (Adj OR $1.70,95 \% \mathrm{CI}=1.24-2.31)$, and those who gave correct responses to the BSE question (Adj OR 1.42, 95\% $\mathrm{CI}=1.05-1.92)$. Pap smear within the last three years was likewise tested in a logistic regression model containing ten covariates. After adjusting, having had Pap smear within the last three years remained significantly higher among women who were older (Adj OR 2.65, 95\% CI = 1.88-3.74), with young children (Adj OR 1.42, 95\% CI = 
Table 5: Practice of breast self examination (BSE) and Pap smear screening by health care and knowledge variables $(n=I 720)$

\begin{tabular}{|c|c|c|c|c|c|c|c|c|}
\hline & \multicolumn{2}{|c|}{ Do BSE every month } & \multirow[b]{2}{*}{$\chi^{2}$} & \multirow[b]{2}{*}{$\mathrm{P}$} & \multicolumn{2}{|c|}{ Pap smear within last 3 yrs } & \multirow[b]{2}{*}{$\chi^{2}$} & \multirow[b]{2}{*}{$\mathrm{P}$} \\
\hline & Yes & No & & & Yes & No & & \\
\hline Contraceptive pill or IUD & & & 1.0 & 0.320 & & & 92.7 & $0.000 * * *$ \\
\hline Currently using $(n=177)$ & $49(27.7)$ & $128(72.3)$ & & & $80(45.2)$ & $97(54.8)$ & & \\
\hline Not using $(n=1543)$ & $370(24.0)$ & $1173(76.0)$ & & & $236(15.3)$ & I 307 (84.7) & & \\
\hline Medical Examination & & & 5.5 & $0.019 *$ & & & 40.9 & 0.000 *** \\
\hline Within last 5 years $(n=775)$ & $210(27.1)$ & $565(72.9)$ & & & $194(25.0)$ & $581(75.0)$ & & \\
\hline Not within last 5 yrs $(n=945)$ & $209(22.1)$ & $736(77.9)$ & & & $122(12.9)$ & $823(87.1)$ & & \\
\hline Pap smear within last 3 years & & & 29.6 & $0.000 * * * *$ & & & & \\
\hline Yes $(n=316)$ & $115(36.4)$ & $201(63.6)$ & & & & & & \\
\hline No $(n=1404)$ & $304(21.7)$ & $1100(78.3)$ & & & & & & \\
\hline Do BSE once a month & & & & & & & 29.6 & $0.000 * * *$ \\
\hline Yes $(n=419)$ & & & & & $115(27.4)$ & $304(72.6)$ & & \\
\hline No $(n=1301)$ & & & & & $20 I(15.4)$ & $1100(84.6)$ & & \\
\hline Answer to BSE question & & & 4.9 & $0.027^{*}$ & & & & \\
\hline Correct $(n=249)$ & $75(30.1)$ & $174(69.9)$ & & & & & & \\
\hline Incorrect $(n=|47|)$ & $344(23.4)$ & $1127(76.6)$ & & & & & & \\
\hline Answer to Pap smear question & & & & & & & 66.0 & $0.000 * * *$ \\
\hline Correct $(n=1334)$ & & & & & $300(22.5)$ & $1034(77.5)$ & & \\
\hline Incorrect $(n=386)$ & & & & & $16(4.1)$ & $370(95.9)$ & & \\
\hline
\end{tabular}

Table 6: Crude and adjusted odds ratios for breast self examination (BSE) and Pap smear screening by selected variables $(\mathrm{n}=\mathbf{1 7 2 0})$

\begin{tabular}{|c|c|c|c|c|c|c|c|c|}
\hline & \multicolumn{4}{|c|}{ Do BSE once a month } & \multicolumn{4}{|c|}{ Have had Pap smear within last 3 years } \\
\hline & OR' & $95 \% \mathrm{Cl}$ & Adj $O R^{2}$ & $95 \% \mathrm{Cl}$ & $\mathrm{OR}^{3}$ & $95 \% \mathrm{Cl}$ & Adj $O R^{4}$ & $95 \% \mathrm{Cl}$ \\
\hline Age (> 30 years, $\leq 30$ years $)$ & 1.53 & $1.23-1.91$ & 1.36 & $1.04-1.79$ & 6.82 & $5.13-9.07$ & 2.65 & $1.88-3.74$ \\
\hline Ethnicity (Malay, Non-Malay) & 1.33 & $1.00-1.77$ & 1.55 & $1.13-2.12$ & 1.90 & $1.44-2.49$ & 1.31 & $0.93-1.86$ \\
\hline Educational attainment ( $\geq$ upper sec, $\leq$ lower sec) & 1.27 & $1.01-1.6 \mid$ & 1.38 & $1.07-1.78$ & 1.51 & $1.18-1.94$ & 0.86 & $0.63-1.18$ \\
\hline Marital status (ever married, never married) & 1.58 & $1.27-1.98$ & 1.25 & $0.92-|.7|$ & 153 & $48.7-478$ & 66.6 & $20.8-213$ \\
\hline Currently pregnant (yes, no) & 1.22 & $0.78-1.89$ & 1.10 & $0.68-1.78$ & 2.41 & $1.57-3.69$ & 1.28 & $0.79-2.07$ \\
\hline Young children (at least one, none) & 1.40 & $1.10-1.77$ & 1.17 & $0.90-1.52$ & 3.33 & $2.58-4.28$ & 1.42 & $1.05-1.91$ \\
\hline Contraceptive pill or IUD (currently using, not using) & 1.21 & $0.86-1.72$ & 0.79 & $0.54-1.17$ & 4.57 & $3.29-6.33$ & 1.62 & $1.12-2.33$ \\
\hline Medical examination within last 5 years (yes, no) & 1.31 & $1.05-1.63$ & 1.17 & $0.93-1.47$ & 2.25 & $1.75-2.89$ & 1.97 & $1.47-2.64$ \\
\hline Pap smear within last 3 years (yes, no) & 2.07 & $1.59-2.69$ & 1.70 & $1.24-2.31$ & - & - & - & - \\
\hline Do BSE once a month (yes, no) & - & - & - & - & 2.07 & $1.59-2.69$ & 1.54 & $1.12-2.16$ \\
\hline Answer to question on BSE (correct, incorrect) & 1.41 & $1.05-1.90$ & 1.42 & $1.05-1.92$ & - & - & - & - \\
\hline Answer to question on Pap smear (correct, incorrect) & - & - & - & - & 6.71 & $4.00-11.2$ & 3.07 & $1.73-5.46$ \\
\hline
\end{tabular}

IFor all variables, the last category was the reference category. ${ }^{2}$ From a logistic regression model that consists of all ten covariates with values given below. For all the covariates, the last category was the reference category. ${ }^{3}$ For all variables, the last category was the reference category, except for ethnicity and educational attainment, for which the first category was the reference category. ${ }^{4}$ From a logistic regression model that consists of all ten covariates with values given below. For all the covariates the last category was the reference category, except for ethnicity and educational attainment, for which the first category was the reference category.

1.05-1.91), on the contraceptive pill or IUD (Adj OR $1.62,95 \% \mathrm{CI}=1.12-2.33$ ), had a medical examination within the last five years (Adj OR 1.97, 95\% CI $=1.47-$ 2.64 ), do BSE monthly (Adj OR 1.54, 95\% CI = 1.12$2.16)$, and answered correctly on the Pap smear question (Adj OR 3.07, 95\% CI = 1.73-5.46). Ever married women had significantly higher odds of having had Pap smear within the last three years, but the result was imprecise (Adj OR 66.6, 95\% CI = 20.8-213). Educational attainment, ethnicity and pregnancy status were not significantly related. 


\section{Discussion}

The selection of factories in this study was not representative of the electronics industry as a whole; moreover, the number of participating factories was small relative to the total number in the country. The women workers in the study were not all randomly selected; a large proportion were volunteers, and as such, this sample was not statistically representative of all the women workers in the participating factories. Voluntary participation could have led to a bias for greater inclusion of women who were more health conscious, or with a greater propensity to seek information on their own health; while women who felt that they had less free time to spare could have been less likely to volunteer. The participation rate in the various factories was uneven, and depended on whether the factory management allowed the workers to take time off from work for the study. In the factories where researchers had to rely on volunteers doing the study in their own time, the participation rate was generally low.

In spite of the weaknesses outlined above, this study is an important one because of the lack of research in Malaysia on the health-seeking behaviour of women workers in general, and electronics factory women workers in particular. Although not statistically representative of the whole industry, the current study provides data from a relatively large number of women workers that could be compared to the nationally representative sample in the 1996 National Health and Morbidity Survey (NHMS), thereby marking its contribution to the existing literature.

\section{Practice of BSE}

The rate of ever doing BSE among the electronics women workers $(44.8 \%)$ was higher than the rates reported from the NHMS for women above 20 years old (34.2\%), urban women $(36.3 \%)$, or women in production $(33.8 \%)$ [6]. It is also higher, but closest to the NHMS rate for women aged 20-54 (39.8\%). The NHMS sample included all women above the age of 20 years, while this sample only had women between the ages of 17 and 55 years. Doing BSE at least once a month, however, was found to be lower among the electronics women in this study (24.4\%) compared to the NHMS rates for women above 20 years $(26.5 \%)$, women in production $(27.7 \%)$ and women aged 20-54 (30.9\%).

Although a higher percentage of women workers in this study had ever done the BSE compared to the NHMS country-wide representative sample, more were also unable to sustain it on a regular basis. It would appear therefore that although this group of women had better than average awareness of and access to information on BSE, they also faced more barriers to practising it regularly.
The BSE rate found in this study, however, is sharply higher than another Malaysian study, where only $1.3 \%$ of 1,303 women were found to practise BSE regularly [13]. Drawn from women who had registered with the Well Person's Clinic at the Outpatient Department of Ipoh Hospital between April 1995 and March 1997, the women were primarily from the lower socioeconomic group, with a majority who were Chinese, between 30-59 years old, married, and housewives, and had never been taught BSE.

Nevertheless, the rate of BSE measured in this study $(24.4 \%)$ as well as that from the NHMS (26.5\%) were low when compared to the 1995 National Health Survey of Australia, where rates were in the region of $60 \%$ and higher (among a sample of 10,179 women aged 18 and above, those who do NOT regularly perform BSE was $38.0 \%$ among the 18-39 year age group, $27.4 \%$ for $40-49$ years, and $25.0 \%$ for 50-59 years) [14]. The BSE once a month rate of $24.4 \%$ was also lower compared to $30.9 \%$ who had done BSE within the past one month from a study of 123 Korean women from a larger convenience sample of 1,202 Asian American women [15]; and compared to $30.6 \%$ who do BSE once a month among a nationwide representative sample of Norwegian female physicians [16].

\section{Practice of pap smear screening}

The rate of ever having had a Pap smear among the electronics women in this study $(25.3 \%)$ was in between the NHMS rates for women aged 20-54 (29.8\%) and production workers $(22.0 \%)$. Likewise, the rate of having had Pap smear within the last three years for the electronics women $(18.4 \%)$ was slightly lower than the NHMS rate for women aged 20-54 years (22.7\%) and slightly higher than the rate for production workers (15.8\%). The Pap smear rate found in this study (18.4\%) was low compared to a study of 470 women staff members in a Malaysian university, where $27.7 \%$ had had a Pap smear within the last three years and $16.0 \%$ had one more than three years ago [17]. The difference could be due to differences in sociodemographic profile, in particular, the higher proportion of never married women in this study $(48.7 \%)$ as compared to the university sample (26.2\%), which was made up of academic, administrative, as well as support staff, who also had greater access to health care through the university health services.

A community-based survey in two residential districts in Singapore among 726 women aged 30-59 years had found a screening rate of $62.4 \%$, with $42 \%$ reporting regular smears [18]. The Malaysian rates are lower compared to Singapore, and of course much lower when compared to those found in developed countries. In 1996, only $2 \%$ aged 25-59 had never had a Pap smear in Uppsala 
County, Sweden, while 41\% aged 25-29 had not had a Pap smear within the last three years, and 21\% aged 3054 had not had one within the last five years [19]. Among the nationally representative sample of 284 Norwegian female physicians, the $54.6 \%$ found to have a Pap smear test once every third year was considered low by the researchers [16]. Likewise, the 55\% Korean American women found to have had a Pap smear in the previous three years was considered a low rate [20].

The present study was limited in that it did not seek to verify self-reported rates of screening with clinical or laboratory records. Other studies have reported discordance between self-reports and medical records. In a random household survey in the Hunter region of New South Wales, Australia, for example, only $61.2 \%$ of the selfreported Pap smears in the last three years could be verified with pathology laboratory records [21]. In the study in Uppsala county, Sweden, those who ever had Pap smear screening were found to have a higher rate of recall accuracy (95\%-99\%) compared to those who never had, among whom $50 \%$ believed they already had one. Furthermore, among those who had a Pap smear within last three years (25-29 year age group) or last five years (3059 year age group), $74 \%$ recalled accurately the time since their last Pap smear, while 57\% of those who had not had a recent smear underestimated the time lapse since the last one.

\section{Factors associated with BSE and Pap smear screening}

In general, the associations found in this study were stronger for Pap smear screening than for BSE practice. Both BSE and Pap smear screening were more likely to be practised by women older than 30 years, but BSE was more commonly practised among Malays and more highly educated women, while Pap smear screening was not significantly associated with ethnicity and educational level after adjusting for other factors.

This BSE pattern is similar to the NHMS, where the practice of BSE was found to be higher among Malay women compared to other ethnic groups, and increased significantly by educational level [6]. It is also similar to the 1995 National Health Survey of Australia, where women who were less educated were found to be less likely to perform BSE regularly [14].

The Pap smear screening pattern in this study, however, is different from the NHMS, where it was found to significantly increase with higher educational levels, and to be higher for women younger than 35 years old compared to older women [11]. In the Singapore community-based study, women who had regular Pap smears were also more likely to be younger, and to have had more years of formal education [18]. Whereas women in these two other studies had varying employment status and were from a range of occupations, the current study only involved women working in factories. The common employment experience may be a factor in lessening the effect of educational attainment in relation to Pap smear screening.

Pap smear screening in this study was significantly related to marital status, but not to pregnancy status, after adjusting for other factors. In fact, the women workers who were never married almost never had the Pap smear. Out of 837 never married women, only three $(0.4 \%)$ had done the Pap smear within the last three years, and nine $(1.1 \%)$ had ever done the Pap smear at all (Table 3). Marital status was a confounding factor in the bivariate analysis of Pap smear screening with age and education, as the younger women tended also to be more highly educated and never married, and all three variables were inversely related to Pap smear screening.

Other Malaysian studies also show the dependence of Pap smear screening on marital status. In the NHMS, only $2.7 \%$ of single women had ever had a Pap smear, compared to $33.4 \%$ married women, $18.3 \%$ divorced women, $9.1 \%$ widowed women, and $10.5 \%$ among women who were cohabiting [11]. In the study among staff members of a local university, Pap smear screening was also significantly associated with an older age, and being married [17].

Other than sociodemographic variables, Pap smear screening was found in this study to be tightly bound to health service delivery variables, being significantly associated with having young children, being on the contraceptive pill or IUD, and having had a medical examination within last five years. Studies in other countries have also found a close association between Pap smear screening and health care utilization indicators $[16,18-20]$. The Singapore community-based study, interestingly, did not find that women who had regular Pap smears were more likely to be married, but they were more likely to have had the last smear as a self-initiated screening test or part of a regular health check-up rather than as part of a postnatal or family planning visit, and also more likely to have visited a general practitioner or a gynaecologist rather than a government polyclinic [18].

In the population-based study in Sweden where attendees of Pap smear screening were compared to non-attendees, those more likely to be non-attendees were women who used condoms or no contraceptives compared to users of oral contraceptives [19]. Likewise, among the Norwegian female physicians, significant correlates of Pap smear screening were being married/cohabitant, having children under 12 years, and using oral contraceptives [16], while 
among the Korean-American women, the strongest correlates of Pap smear in the previous two years were being married and employed, and having had a routine checkup within the last two years, which indicated either access to health care or preventive health behaviour [20].

In contrast to the pattern of Pap smear screening, BSE among the electronics women workers of this study was not related to marital status, being currently pregnant, having young children, being on the contraceptive pill or IUD, or having had a medical examination in the last five years. It was found to be less dependent on health service utilisation, and therefore, also to have less bias against never married women.

Nevertheless, this constitutes a departure from the national trend in the NHMS, where the higher BSE rate among married women compared to single women was attributed to opportunity and access to information and being taught BSE, which in turn was attributed to programme policy [6]. In the 1995 National Health Survey of Australia, also, previously married and never married women were significantly less likely than currently married women to perform BSE regularly [14].

\section{Knowledge questions}

In this study, correct responses to the question on the correct time of the month to do BSE was significantly associated with practising BSE every month. However, on the whole, many more women gave incorrect $(n=1471)$ than correct responses $(n=249)$; and even among those who do BSE, more gave incorrect answers $(82.1 \%)$ than correct answers (17.9\%) (Table 4$)$. In other words, most women, including women who do BSE, do not know when is the correct time for doing BSE, although compared to women who do not do BSE, they had better knowledge.

Knowledge that Pap smear is a test for cervical cancer was also significantly associated with having had one within the last three years, but in contrast to the BSE question, there were many more women who gave correct $(\mathrm{n}=$ $1334)$ than incorrect $(n=386)$ responses (Table 4$)$. Even among those who had not had a Pap smear within the last three years, more gave correct answers (74\%) than incorrect answers $(26 \%)$.

This is congruent with the finding in the NHMS, where $86.6 \%$ of women who had Pap smear knew the reason for doing so [11]. Similarly, the study of university staff members also found that Pap smear screening was significantly associated with having a higher level of health knowledge, and showing positive self-interest towards health [17].

A significant association was found in this study between having had Pap smear within the last three years and prac- tising BSE monthly. This association was also noted in the NHMS, where $74 \%$ of the women who had undergone Pap smear screening also practised BSE, as compared to $43 \%$ of those who had not done a Pap smear [11]. This may be explained as the tendency for individuals who are aware and concerned about their health to be motivated toward both BSE and Pap smear screening practice.

\section{Conclusion}

The group of electronics women workers in this study is drawn from an important segment of the Malaysian workforce. Although they constitute a group from the lower socio-economic strata, nevertheless, they are largely urban-based and draw a higher wage than women production workers in many other industries.

The sample was not representative of the electronics industry as a whole, and the large proportion of respondents who were volunteers could have led to a tendency to include women who were more active in seeking health information and in accessing health care. As such, the lower BSE and Pap smear screening rates found among these women as compared to the national average for women of a similar age group is a cause for greater concern.

In general, there were more women who know about BSE and the Pap smear than those who conduct them at the proper intervals as part of a regular preventive health strategy. There could be barriers to the regular practice of BSE and Pap smear that are specific to women production workers, and it would be important to identify these barriers, which may include psycho-social as well as economic ones, so that educational and promotional strategies could be more effective. Factory-based cancer screening and education programmes could contribute toward improving health knowledge and screening practices of women production workers.

The association between Pap smear screening and health service variables reflect the success of governmental strategy to disseminate it through postnatal and family planning service outlets. However, its close connection with marital status, to the practical exclusion of single women, is an indication that the health services have not been successful in widening its availability to all women.

The practice of BSE, on the other hand, was not found to be dependent on health service variables, but on educational level. This implies that there is wider interest in this than could be reached through postnatal and family planning services, and that this interest is linked to education. Adequate information and educational services should particularly reach out to women with lower educational levels, and young and single women. 
Indeed, the large proportions who did not know the best time for doing BSE, even among those who were practising it once a month, reflect that the methods employed to disseminate information on this subject should be thoroughly reviewed. Many women are taught BSE during one-off postnatal visits, although those who are on oral contraceptives and the IUD receive reinforcement each time they visit the family planning clinic.

In any case, governmental policy on the promotion of BSE should be reviewed in light of recent research findings. Whether or not BSE should be taught and promoted, and how it should be done, should be ascertained through a thorough assessment of current practice and its effects. Information and knowledge about breast cancer could still be widely disseminated, whether or not BSE is advocated, and women should still be encouraged to be aware of their breasts, and any symptoms which could arise.

\section{Competing Interests}

None declared.

\section{Author's Contributions}

RS was the leading investigator and the coordinator of the USM-Kel Centre, CHL was the coordinator of the UPM Centre, KS was the coordinator of the UKM Centre, and IO was the coordinator of the USM-Pg Centre. All authors participated in the conception and design of the study. KS merged and cleaned the data, CHL analysed the data and wrote the draft manuscript, and all authors read, commented on and approved the manuscript.

\section{Acknowledgements}

This study was funded by the Malaysian Ministry of Science, Technology and Environment Intensification of Research in Priority Areas (IRPA) (Medical Sector) Programme for the project entitled "A Study of Working Women's Health Status in Relation to Lifestyles". The participating institutions were Universiti Sains Malaysia (USM) Penang and Kelantan campuses, Universiti Kebangsaan Malaysia (UKM), Universiti Putra Malaysia (UPM), and the National Institute of Occupational Safety and Health (NIOSH).

\section{References}

I. Baxter $\mathrm{N}$ and with the Canadian Task Force on Preventive Health Care: Preventive health care, 200 I update: should women be routinely taught breast self-examination to screen for breast cancer? Canadian Medical Association Journal 200I, I 64: I837-I846.

2. Thomas DB, Gao DL, Ray RM, Wang WW, Allison C], Chen FL, Porter $\mathrm{P}, \mathrm{Hu}$ YW, Zhao GL and Pan LD: Randomized trial of breast self-examination in Shanghai: final results Journal of the National Cancer Institute 2002, 94:|445-| 457.

3. Larkin M: Breast self-examination does more harm than good, says task force Lancet 2001, 357:2109.

4. Bradbury J: Stop teaching breast self-examination, say Canadian experts Lancet Oncology 200I, 2:46I.

5. The Star, Malaysia . 6th October 2002

6. Narimah A, Rugayah HB, Tahir A and Maimunah AH: Breast Examination, National Health and Morbidity Survey 1996 Volume 20 Kuala Lumpur, Public Health Institute, Ministry of Health, Malaysia 1999.

7. Forbes C, Jepson R and Martin-Hirsch P: Interventions targeted at women to encourage the uptake of cervical screening (Pro- tocol for a Cochrane Review) In: The Cochrane Library Oxford: Update Software; 2001.

8. Sankaranarayanan R, Budukh AM and Rajkumar R: Effective screening programmes for cervical cancer in low- and middleincome developing countries Bulletin of the World Health Organization 2001, 79:954-962.

9. Ministry of Health, Malaysia: Malaysia's Health 1999: Technical Report of the Director-General of Health, Malaysia Kuala Lumpur, Ministry of Health, Malaysia 1999.

10. Cheah PL and Looi LM: Carcinoma of the uterine cervix: a review of its pathology and commentary on the problem in Malaysians Malaysian Journal of Pathology 1999, 2 1:1-15.

II. Narimah A, Rugayah HB, Tahir A and Maimunah AH: Cervical cancer screening, National Health and Morbidity Survey 1996 Volume 19 Kuala Lumpur: Public Health Institute, Ministry of Health, Malaysia 1999.

12. Ejlertsson G, Eden L and Leden I: Predictors of positive health in disability pensioners: a population-based questionnaire study using positive odds ratio BMC Public Health 2002, 2:20.

13. Chan SC: Practice of breast self-examination amongst women attending a Malaysian well person's clinic Medical Journal of Malaysia 1999, 54:433-437.

14. Mohammad S and Singh GK: Sociodemographic variations in breast cancer screening behavior among Australian women: results from the 1995 national health survey Preventive Medicine 2002, 35: I74- 180.

15. Sadler GR, Ryujin LT, Ko CM and Nguyen E: Korean women: breast cancer knowledge, attitudes and behaviors BMC Public Health 200I, I:7.

16. Rosvold EO, Hjartaker A, Bjertness $E$ and Lund $E$ : Breast selfexamination and cervical cancer testing among Norwegian female physicians Social Science and Medicine 200I, 52:249-258.

17. Shamsuddin K and Zailiza S: Factors associated with Pap smear screening among women workers in Universiti Kebangsaan Malaysia [abstract] Medical Journal of Malaysia 200I, 56(suppl B): 115 .

18. Lee J, Seow A, Ling SL and Lee HP: Improving adherence to regular Pap smear screening among Asian women: a population-based study in Singapore Health Education \& Behavior 2002, 29:207-218.

19. Eaker S, Adami HO and Sparen P: Reasons women do not attend screening for cervical cancer: a population-based study in Sweden Preventive Medicine 200I, 32:482-49I

20. Wismer BA, Moskowitz JM, Chen AM, Kang SH, Tager IB, Min K, Novotny TE and Lew R: Rates and independent correlates of Pap smear testing among Korean-American women American Journal of Public Health 1998, 88:656-660.

21. Bowman JA, Sanson-Fisher R and Redman S: The accuracy of selfreported Pap smear utilisation Social Science and Medicine 1997, 44:969-976.

\section{Pre-publication history}

The pre-publication history for this paper can be accessed here:

\section{http://www.biomedcentral.com/1472-6874/3/3/prepub}

Publish with Bio Med Central and every scientist can read your work free of charge

"BioMed Central will be the most significant development for disseminating the results of biomedical research in our lifetime. "

Sir Paul Nurse, Cancer Research UK

Your research papers will be:

- available free of charge to the entire biomedical community

- peer reviewed and published immediately upon acceptance

- cited in PubMed and archived on PubMed Central

- yours - you keep the copyright
BioMedcentral 